\title{
FITOTERAPIA: TOXICIDADE E DESINFORMAÇÃO
}

Bruna Soares de Souza Lima; Larissa Martins de Sena; Williana de Paula; Kainne Gomes de Souza Santos; Maurício Hanani Pinho Coelho; Rauane Silva Pires. Fitoterapia: toxicidade e desinformação. Revista Saúde Dinâmica, vol. 9, núm. 3, 2021. Faculdade Dinâmica do Vale do Piranga.

\section{SAÚDE DINÂMICA - Revista Científica Eletrônica FACULDADE DINÂMICA DO VALE DO PIRANGA}

9ạ Edição 2021 | Ano III - no 3 | ISSN - 2675-133X 


\author{
Fitoterapia: toxicidade e desinformação \\ Phytotherapy: toxicity and disinformation \\ Bruna Soares de Souza Lima ${ }^{l}$; Larissa Martins de Sena ${ }^{l}$; Williana de Paula ; Kainne Gomes de \\ Souza Santos ${ }^{l}$; Maurício Hanani Pinho Coelho ${ }^{l}$; Rauane Silva Pires ${ }^{l}$. \\ 'Escola de Medicina - Faculdade Dinâmica do Vale do Piranga (FADIP) \\ Autor correspondente: brunasoaressl@yahoo.com.br
}

\title{
Resumo
}

O uso de plantas para o tratamento de doenças é uma prática antiga e que continua presente na sociedade até os dias atuais, cenário comprovado pelas políticas implementadas para a inserção da Fitoterapia na saúde pública. Porém, as plantas medicinais podem ser tóxicas, considerando seus princípios ativos, de modo que, esse é um assunto relevante, dada a frequência e aumento da sua utilização, e a falta de conhecimento, por parte da população, acerca dos perigos decorrentes do uso irregular desses compostos. Por essa razão, esse trabalho tem como objetivos: descrever os princípios ativos das principais plantas medicinais utilizadas no Brasil, compreender o mecanismo relacionado à hepatotoxicidade e apresentar os efeitos adversos e os riscos do uso indiscriminado desses fitoterápicos. Trata-se de um estudo narrativo, realizado por meio do acesso aos bancos de dados SciELO e PubMed, através das seguintes palavras chaves: Hibisco, Erva cidreira, Cavalinha, Sacaca, Chá verde, Kava-Kava, Porangaba, Valeriana, Unha de Gato, Poejo e Cáscara Sagrada, e associação com as lesões hepáticas. Os princípios ativos dos fitoterápicos, citados anteriormente, são diversos, de modo que podem ser utilizados para várias finalidades. No entanto, o uso indiscriminado desses compostos mostrou potencial hepatotoxicidade, visto que o fígado é o órgão responsável pela metabolização dos xenobióticos. Diante disso, é imprescindível promover maior disseminação das informações acerca do uso dos fitoterápicos para a população, bem como é necessário ampliar o entendimento sobre os possíveis efeitos adversos, inclusive entre os profissionais da saúde, para evitar complicações decorrentes da má administração.

Palavras-chave: hepatotoxicidade, figado, hepatócitos, xenobióticos, fitoterapia e plantas medicinais.

\begin{abstract}
The use of plants for the treatment of diseases is an old practice and which continues to be present in society nowadays, a scenario proven by the policies implemented for the insertion of Phytotherapy in public health. However, medicinal plants can be toxic, considering their active ingredients, so this is a relevant issue, given the frequency and increase of its use, and the lack of knowledge, on the part of the population, about the dangers arising from the use irregular these compounds. For this reason, this work aims to describe the active principles of the main medicinal plants used in Brazil, understand the mechanism related to hepatotoxicity and present the adverse effects and risks of the indiscriminate use of these herbal medicines. This is a narrative study, carried out through access to the SciELO and PubMed databases, using the following keywords: Hibisco, Erva cidreira, Cavalinha, Sacaca, Chá verde, Kava-Kava, Porangaba, Valeriana, Unha de Gato, Poejo e Cáscara Sagrada, and association with liver injuries. The active principles of herbal medicines, mentioned above, are diverse, so they can be used for various purposes. However, the indiscriminate use of these compounds showed potential hepatotoxicity, since the liver is the organ responsible for the metabolism of xenobiotics. Given this, it is essential to promote greater dissemination of information about the use of herbal medicines to the population, as well as it is necessary to broaden the understanding of possible adverse effects, including health professionals themselves, to avoid complications resulting from maladministration.
\end{abstract}

Key words: hepatotoxicity, liver, hepatocytes, xenobiotics, medicines and medicinal plants 


\section{INTRODUÇÃO}

O uso de plantas medicinais para o tratamento de doenças e/ou amenização de sintomas é uma prática que acompanha a humanidade antes mesmo da escrita. No início, o homem realizava experimentos com as plantas, utilizando-as como alimento ou remédio; e, a partir desse momento, estabelecia as relações de benefícios e/ou prejuízos. Ao longo dos séculos e de várias pesquisas, os efeitos das plantas medicinais no organismo humano foram se tornando mais conhecidos e fundamentados. Entretanto, as plantas medicinais e seus princípios ativos, considerando a fonte natural da qual são adquiridos, culminam com a falsa ideia: "se é natural, não faz mal", o que consiste em um pensamento perigoso (JUNIOR, et al., 2005; SILVA, 2016).

Muitas das plantas medicinais utilizadas atualmente são as mesmas que eram usadas há vários séculos. Dentre as mais populares estão: Hibisco (Hibiscus sabdariffa), Erva cidreira (Melissa officinalis), Cavalinha (Equisetum arvense L.), Sacaca (Croton cajucara), Chá verde (Camellia sinensis), Kava-Kava (Piper methysticum), Porangaba (Cordia salicifolia), Valeriana (Valeriana officinallis), Unha de Gato (Uncaria tomentosa), Poejo (Mentha pulegium) e Cáscara Sagrada (Rhamnus purshiana). O uso dessas e de outras plantas medicinais é uma realidade em diversos países, entre os quais o Brasil, onde, em 2006, foi criada a Política Nacional de Plantas Medicinais e Fitoterápicos, que oferece aos usuários do Sistema Único de Saúde (SUS) a fitoterapia com acesso seguro e uso racional (BRASIL, 2006). Ainda nesse sentido, estimativas da Organização Mundial da Saúde (OMS) indicam que até $80 \%$ da população de países em desenvolvimento confiam na Medicina Complementar ou Alternativa (MAC) para o cuidado médico primário, devido à tradição cultural ou falta de alternativas (BAGOZZI, 2005; BARACHO, 2016, p. 88), fato que sinaliza para um possível aumento do uso desses fitoterápicos. Por outro lado, outros estudos têm mostrado que, em países em desenvolvimento, aproximadamente, $3 \%$ da população urbana é afetada, anualmente, pela toxicidade dessas plantas, quando as mesmas são utilizadas indiscriminadamente (SINITOX, 2003), destacando nesse sentido o fígado, cuja função relaciona-se com a metabolização dos xenobióticos. Pesquisas realizadas no Reino Unido sugerem uma incidência de evento adverso atribuído a fitoterápicos em torno de 7\% (ABBOTT et. al., 1996; PINN, 2001; ARRAIS, 2008) demonstrando que, apesar de ser uma alternativa terapêutica positiva, algumas precauções devem ser consideradas e as informações divulgadas, visando a utilização segura desses fitoterápicos. 
Considerando o aumento do uso das plantas medicinais e o potencial das mesmas para causar intoxicação, o estudo justifica-se pela necessidade de promover uma maior conscientização da população, que faz uso desses compostos, para uma prática mais segura. Dessa forma, tem-se como objetivos específicos desse estudo: descrever os princípios ativos das principais plantas medicinais utilizadas no Brasil, compreender o mecanismo relacionado à hepatotoxicidade e apresentar os efeitos adversos e os riscos do uso indiscriminado desses fitoterápicos.

\section{MATERIAIS E MÉTODOS}

O presente artigo trata-se de uma revisão narrativa, descritiva e qualitativa cuja obtenção dos dados foi realizada nos bancos de dados SciELO e PubMed. Na base de dados SciELO foram utilizados como descritores: "hepatotoxicidade", "fígado", "hepatócitos", "xenobióticos", "fitoterápicos" e "plantas medicinais"; e na base de dados PubMed foram utilizadas as seguintes palavras chave: "hepatic adverse effects" e "phytotherapy". Para compreender, de forma mais específica, as associações dos efeitos adversos causados por determinadas plantas foram utilizadas, ainda, as seguintes combinações: "Rhamnus purshiana" and "hepatic adverses effects", "Croton cajucara" and "hepatic adverses effects", "Piper methysticum" and "hepatic adverses effects" e "Camellia sinensis" and "hepatic adverses effects". Além desses, foram utilizados livros que abordavam sobre a metabolização dos xenobióticos no fígado.

Foram selecionados artigos em português ou inglês, cujos textos completos estavam disponíveis on-line e publicados a partir de 1997, nesse caso pretendendo descrever sobre as principais atualizações sobre o tema. Considerando esses critérios de inclusão foram elegidos os manuscritos que permitiram: caracterizar os princípios ativos, as funções e possíveis efeitos adversos das principais plantas medicinais; e compreender o processo de metabolização no fígado bem como suas reações.

Entre os critérios de exclusão podem-se citar artigos publicados em período anterior ao especificado nos critérios de inclusão; manuscritos publicados em idiomas que não o português e inglês e os artigos cujos temas não abordavam o assunto de interesse. 


\section{DESENVOLVIMENTO}

O uso de plantas para o tratamento de doenças não é uma prática recente, sendo o primeiro registro entre 2838-2698 a. C, na China; desde então, essa prática cresce cada vez mais na sociedade. Segundo dados do Ministério da Saúde, entre 2013 e 2015, a busca por tratamentos à base de plantas medicinais e medicamentos fitoterápicos pelo SUS mais que dobrou: o crescimento foi de 161\% (MAZIERO, 2017). Esse crescimento está associado a vários fatores, mas, principalmente, a crença de que os produtos naturais são isentos de toxicidade e que são eficazes para o tratamento de doenças novas e antigas, cujo tratamento convencional é insatisfatório (SBH, 2011). Um dos efeitos desse crescimento refere-se à criação do Programa Nacional de Plantas Medicinais e Fitoterápicos que tem como objetivo promover o uso sustentável da biodiversidade do Brasil e melhorar a qualidade de vida da população por meio da ampliação das opções terapêuticas dos usuários do Sistema Único de Saúde (SUS) (BRASIL, 2006).

Com a expansão do uso desses fitoterápicos, muitas plantas e chás tornaram-se extensamente conhecidos e são constantemente utilizados pela população. Entre eles, pode-se citar: Hibisco, Erva cidreira, Cavalinha, Sacaca, Chá verde, Kava-Kava, Porangaba, Valeriana, Unha de Gato, Poejo e Cáscara Sagrada. Cada um desses chás possui seu próprio princípio ativo, suas funções e seus possíveis riscos para o organismo, sendo o fígado um dos órgãos mais afetados, no caso de má administração.

\section{Classificação das plantas, seus princípios ativos, funções e possíveis efeitos adversos}

A cavalinha (Equisetum arvense L.) é considerada um dos melhores diuréticos de origem vegetal, de forma que, pode ser usada para o tratamento adjuvante da hipertensão e terapia complementar na perda peso. Também tem efeito adstringente e pode ser utilizada no tratamento das doenças do sistema circulatório. É contraindicada para pessoas com insuficiência cardíaca e/ou renal e não é indicada para crianças, mulheres grávidas e mulheres amamentando (BIERNATH, 2017). Alterações hepáticas aparecem entre três e 18 semanas após início do seu uso, geralmente quando utilizada em doses superiores a 600mg/dia (SBH, 2011).

O chá de Porangaba (Cordia salicifolia), que também é conhecida como chá de bugre, cafezinho e chá de mato (SBH, 2011), é preparado com a folha da planta, por infusão. Entre as 
substâncias com princípio ativo conhecido, destacam-se: a cafeína, a alantoína, o ácido alantóico, o glicosídeo como a consolidina e os taninos. É utilizada na fitoterapia brasileira como diurético, febrífugo, estimulante circulatório e também como inibidora do apetite, embora poucos relatos científicos comprovem tais atividades (ASSONUMA, 2009). Entre os potenciais prejuízos do seu uso destaca-se a possibilidade de causar hepatite aguda tipo hepatocelular, com elevações discretas das aminotranferases e rápida normalização destas com a suspensão do chá (SBH, 2011). Por apresentar cafeína em sua composição, pode causar insônia, enxaqueca e hipertensão (CAPARROZ-ASSEF et al., 2005).

A Valeriana (Valeriana officinallis): também conhecida como erva de São Jorge e erva dos gatos, é uma planta cujo chá é preparado a partir das raízes. Tem como princípios ativos os valepotriatos (valtrato, isovaltrato e dehidrovaltrato), sesquiterpenos e lignanas (SOLDATELLI, 2010, p. 93). É usada no tratamento da ansiedade, insônia, melhoraria do sono, resfriado comum, gripe, entre outros (SOLDATELLI, 2010, p. 91). Com administração irregular, pode causar hepatite aguda, que pode ser fulminante (SBH, 2011). Cefaleia, ressaca e sintomas do trato gastrointestinal são outros efeitos colaterais (SILVEIRA, 2007, p. 30). De acordo com o site Horto Didático de plantas medicinais do HU/CCS, a dosagem recomendada para uso dependerá da parte da planta que será usada. Quando for a raiz, pode ser utilizado 1 a $3 \mathrm{~g}$, até três vezes por dia; para a tintura da planta, é recomendado o uso de 1 a $3 \mathrm{ml}$; e, se o extrato for usado, a quantidade recomendada é de 2 a $3 \mathrm{~g}$.

A Sacaca (Croton cajucara) apresenta o linalol, sabineno, estragol, linearisina, magnoflorina, ácido aleuritórico (tripenóide) como princípios ativos. O clerodano transdesidrocrotonina (DCTN) é o principal constituinte do chá das cascas da Sacaca, mas o mesmo pode ser consumido através da ingestão de pílulas (pó das cascas), apesar de o rendimento ser menor (JUNIOR, et al., 2005). É utilizada na medicina para tratar obesidade e hipercolesterolemia. O uso indevido dessa planta pode causar hepatite aguda, crônica e mesmo fulminante (SBH, 2011).

O chá de hibisco, Hibiscus sabdariffa, é preparado com o cálice do botão seco da flor. Apresenta substâncias antioxidantes, entre as quais os flavonoides, especialmente as antocianinas, que têm efeito cardioprotetor, vasodilatador e evitam o acúmulo de gorduras. Costuma ser utilizado, ainda, com vistas ao emagrecimento e aumento da diurese, auxiliando assim, o controle da pressão arterial. Além disso, o chá de hibisco pode ser utilizado no controle do colesterol. O seu consumo requer atenção, principalmente para aqueles que apresentam 
alterações na pressão e também para mulheres em idade fértil. Pode causar toxicidade se for consumido em doses excessivas (KIMURA, 2015). No site Horto Didático de plantas medicinais do HU/CCS é recomendado o uso de 1 colher de sopa de cálices jovens em 1 xícara de água, quando preparado por infusão, podendo ser tomado três vezes ao dia, ou 1 colher de sopa de flores para 2 copos de água, quando processado por decocção, podendo, também, ser tomado três vezes ao dia.

A Erva Cidreira (Melissa officinalis) é uma planta da família da hortelã e do boldo. Ela possui ação sedativa, ligeiramente hipnótica e antioxidante e, ainda têm ação calmante, melhorando casos de insônia, ansiedade, depressão e estresse. Esse chá também é indicado para asmáticos, portadores de hipertireoidismo, hipertensos, entre outros. O consumo de quantidades elevadas de erva cidreira pode estar associado à bradicardia e à hipotensão, bem como pode relacionar-se à hepatotoxicidade (VILAR, 2019). Segundo o site Horto Didático de plantas medicinais do HU/CCS, a dosagem recomendada para uso, quando preparado por infusão, é de 2 a 3 g da erva para cada xícara de água.

O Poejo (Mentha pulegium) é uma herbácea com flores pequenas, branco-lilases, em inflorescências axilares, com odor peculiar. As folhas e inflorescências são as partes utilizadas no preparo do chá. É popularmente utilizado no tratamento de resfriados e gripe, e atua em sintomas como a febre, devido à sudorese que provoca. É considerada, também, abortiva, carminativa, digestiva, vermífuga, expectorante, antisséptico, antiespasmódico, emenagogo e repelente de insetos (pulegona). É usado ainda no tratamento de cólicas, dor de dente e congestão torácica. Relatos comprovam que a planta promove irritação do útero, podendo culminar com as contrações. Pode provocar hemorragia, e até mesmo a morte. Suspeita-se que a pulegona seja a responsável pelos efeitos tóxicos desse chá, por ser convertida em um metabólito tóxico, no fígado. Essa substância é capaz de causar depleção da glutationa hepática, provocando insuficiência do órgão (OLIVEIRA, 2015). A pulegona é metabolizada pelo sistema enzimático CYP2E1 e, quando administrada de maneira errada, pode produzir hepatite aguda e mesmo hepatite fulminante (BOHAN, et al., 2002; SBH, 2011). Segundo o site Horto Didático de plantas medicinais do HU/CCS, é recomendado utilizar 1 colher de chá de planta fresca em 1 xícara de água; podendo ser tomado 2 xícaras ao dia, durante, no máximo, 2 semanas.

No caso da Cáscara Sagrada (Rhamnus purshiana) as partes utilizadas para fazer o chá são a casca do caule e dos ramos. É utilizada para constipação ocasional, pois atua aumentando 
os movimentos intestinais, e facilita a eliminação das fezes (VILAR, 2019). O uso crônico ou abusivo do fitoterápico tem sido implicado como causa de hepatite colestática, e também associado a casos de hepatopatia crônica (SBH, 2011). A dosagem diária usual é de 100 a 500 mg de extrato seco; 0,5 a 2 g quando em pó, 0,3 a $3 \mathrm{~mL}$ de extrato fluido e 1 a $10 \mathrm{~mL}$ da tintura (BATISTUZZO, et al., 2006; DARROZ, et al., 2014).

Da Unha de Gato (Uncaria tomentosa) são usadas a casca, as folhas e as raízes para realizar a infusão. Cabe ressaltar que muitas variedades da unha-de-gato mexicanas possuem propriedades tóxicas. Seu uso já foi relatado para o tratamento de amigdalites, artrite, sinusite, bursite, rinite e problemas digestivos, reumáticos e musculares; possui atividade antioxidante, anti-inflamatória, anticancerígena, imunoestimulante e também auxilia na reparação de células (VILAR, 2019). No entanto, alguns estudos mostraram quadro de hepatite aguda tipo hepatocelular, desenvolvida com seu uso, havendo recuperação completa com a suspensão da substância (SBH, 2011).

O princípio ativo do chá verde (Camellia sinensis) é a Catequina. É usualmente utilizado como antioxidante, anti-inflamatório, anti hipertensivo, antidiabético e antimutagênico (BASU et al, 2007; MORAIS, 2012). Em grandes doses pode causar insônia, irritabilidade, náuseas, acidez no estômago, vômitos, taquicardia e aumento do ritmo cardíaco, por exemplo. Além disso, pode interferir na absorção de ferro. Na literatura, 34 casos de hepatotoxicidade relacionada à ingestão deste chá foram descritos entre 1999 e 2008. A lesão hepática geralmente é do tipo hepato-celular, de evolução benigna. Os metabólitos reativos são as catequinas, sendo que a sua forma de extração e preparação favorecem a hepatotoxicidade (SBH, 2011). Jocelem Mastrodi Salgado, professora da Escola Superior de Agricultura "Luiz de Queiroz" Universidade de São Paulo, relatou numa entrevista divulgada na Revista Espaço Aberto que: “A ingestão diária de $320 \mathrm{mg}$ a $350 \mathrm{mg}$ de polifenois é suficiente para fornecer todos os benefícios almejados. Isso corresponde a dois copos do chá solúvel: cerca de $10 \mathrm{~g}$ da erva e 200ml de água” (SALGADO; 2021).

As propriedades da Kava-Kava (Piper methysticum) auxiliam no combate a ansiedade e tratamentos de estresse e insônia. As kavalactonas, como são conhecidas, são usadas como alternativa ao uso de benzodiazepínicos, prescritos para o tratamento da ansiedade. Durante os anos de 1999 a 2002, a Kava-Kava compôs a lista dos 10 medicamentos fitoterápicos mais vendidos no Brasil (BARBOSA, 2013). Vários casos de hepatite aguda têm sido descritos, alguns com evolução grave requerendo transplante hepático e outro evoluindo com a morte 
(SBH, 2011). Ensaios com animais experimentais demonstraram que a administração de 800 mg de kavalactona/kg/dia por 8 dias é considerada hepatotóxico (FERREIRA, 2019).

\section{Processo de metabolização no fígado e suas reações}

O fígado é considerado a principal "usina de depuração metabólica" dos compostos químicos endógenos e xenobióticos (GOODMAN, 2012). Por ser responsável pela metabolização dos fitoterápicos e seus compostos, ele é o principal órgão acometido, em caso de toxicidade.

Após serem absorvidos pelo intestino delgado, esses compostos chegam ao fígado pela veia porta. Os hepatócitos, células responsáveis pela metabolização dos xenobióticos, internalizam, assim, as moléculas fitoterápicas, que se fixam na camada lipídica, onde sofrem oxidação pelas enzimas da fase 1. Em seguida, ocorre a fase 2, na qual os compostos sofrem conjugação pelas UDP-glicuronil transferase (UGTs) ou pelas tranferases citosólicas e são transferidos para a corrente sanguínea (YANG et al., 2017).

No caso de intoxicação, as substâncias tóxicas são responsáveis pela lesão dos hepatócitos, por meio da formação dos radicais livres ou metabólitos, que podem causar a peroxidação dos lipídeos da membrana (LUNARDELLI et al., 2020). Pode ocorrer: febre baixa, icterícia, colúria e vômitos; podendo evoluir para hepatite, síndrome de obstrução sinusoidal e cirrose hepática (BALLOTIN et al., 2021).

A associação desses efeitos foi comprovada com inúmeros relatos entre os quais o caso de um adolescente norte-americano, que utilizou a Camellia sinensis no tratamento para perder peso. O paciente chegou ao pronto socorro com icterícia e, após a realização de uma biópsia hepática, foi evidenciada a inflamação aguda e crônica, em consequência da necrose de hepatócitos e colestase, seguido de falência hepática, devido ao uso exagerado do fitoterápico (PATEL et al, 2013).

Os efeitos tóxicos da Piper methysticum no fígado foram comprovados em camundongos, os quais receberam, aproximadamente, $800 \mathrm{mg}$ de kavalactona (constituinte do Piper methysticum) $/ \mathrm{kg} /$ dia por 8 dias, o que causou um aumento significativo no peso do fígado (YAMAZAKI, 2008). Esse efeito ocorre pelo aumento da expressão genética da mRNA do CYP1A1 e se relaciona à hipertrofia e hiperplasia dos hepatócitos e, assim, aumento do órgão (CHAUDARY et al, 2009). 
Graim et al, 2008 analisaram os efeitos da ingestão excessiva de Croton cajucara no organismo de ratos. Administraram $0,1 \mathrm{ml} / 100 \mathrm{~g}$ de Sacaca em pó e mostraram necrose hepatocelular, após 56 dias de uso, que pode culminar com hepatite, a longo prazo.

No caso da Rhamnus purshiana, a hepatotoxicidade foi comprovada pela administração da planta por 34 dias em camundongos, o que resultou em inchaço hepatocelular; confirmado por microscopia eletrônica, cuja causa apontada foram os depósitos de glicogênio no citoplasma dos hepatócitos (LICHTENSTEIGER et al, 1997).

\section{Efeitos do uso indiscriminado e desinformado de fitoterápicos}

Com o crescimento da utilização e desenvolvimento de medicamentos fitoterápicos, a Organização Mundial da Saúde (OMS) tem mostrado interesse em melhorar as condições no que tange a garantia da qualidade, segurança e eficácia destes produtos (BRASIL, 2006). Esse interesse demonstrado pela OMS é de significativa importância, visto que, no Brasil, a presença de uma grande biodiversidade em flora e o baixo custo relativo ao uso de fitoterápicos fortalece a adesão da população a essa prática. $O$ perigo se encontra no fato desses usuários não terem a informação adequada para o uso correto dessas plantas medicinais, o que aumenta a possibilidade de intoxicação (RODRIGUES et al., 2011; COLET et al., 2015; PEDROSO et al., 2021).

Diante disso, é imprescindível promover maior disseminação das informações acerca do uso dos fitoterápicos para a população, bem como é necessário ampliar o entendimento sobre os possíveis efeitos adversos, inclusive aos próprios profissionais da saúde, visto que, eles, muitas vezes, não reconhecem esses efeitos e, em algumas situações, os pacientes não informam o uso de plantas durante a consulta (RAHMAN et al., 2002; ADUSUMILLI et al., 2002; SILVEIRA, 2007) por acreditarem que as plantas não causam prejuízos à saúde.

\section{CONCLUSÃO}

O artigo permitiu concluir que, de fato, com o perpassar dos anos, houve um aumento do consumo de fitoterápicos; o que poderia ser justificado pela busca por terapias mais naturais e/ou menos invasivas, além de mais acessíveis.

Os fitoterápicos são utilizados, na atualidade, para diversas finalidades: controle da pressão arterial e do colesterol, como diurético, para ansiedade e insônia, além de antioxidante e no auxílio para o emagrecimento. 
No entanto, o uso indiscriminado desses compostos pode promover efeitos colaterais diversos, desde leves até graves e fatais. Nesse contexto destaca-se o fígado, um dos principais órgãos acometidos, em casos de intoxicação, considerando sua atuação na metabolização de tais substâncias.

Sendo assim, é fundamental promover a divulgação do programa de farmacovigilância, que possui como objetivo a detecção precoce dos efeitos, indesejados e desconhecidos, dos fitoterápicos.

Além disso, é necessário apoiar estudos que vislumbrem o aprofundamento no tema, a fim de que, medicações fitoterápicas não sejam configuradas como um agravo no processo saúde doença.

\section{REFERÊNCIAS}

ABBOT, N. C; WHITE A. R; ERNST E. Complementary medicine. Nature, United Kingdom, v. 381, n. 97, p. 361, maio/1996. Disponível em: https://www.nature.com/articles/381361a0.pdf.

ADUSUMILLI P. S., LEE B., PAREKH K, FARRELLY P. A. Acalculuos eosinophilic cholecystitis from herbal medicine: A review of adverse effects of herbal medicine in surgical patients. Surgery, v. 131, n. 3, p. 352-356, mar./2002. DOI: 10.1067/msy.2002.121540.

ARRAIS, P. F. D; BANDEIRA M. A. M; ARRAIS, P. S. D. Farmacovigilância e reações adversas às plantas medicinais e fitoterápicos: uma realidade. Revista Brasileira de Farmacognosia, João Pessoa, v. 18, n. 4, p. 618-626, out./2008. Disponível em: https://www.scielo.br/scielo.php?script=sci_arttext\&amp;pid=S0102- 695X2008000400021. Acesso em: 8 set. 2020.

ASSONUMA, M. M. Determinação de Alantoína e Avaliação Farmacológica de Cordia ecalyculata VELL. (Chá de Bugre). Dissertação (Mestrado em Química) - Universidade Estadual de Paulista. Araraquara, p. 6. 2009. Disponível em:

http://livros01.livrosgratis.com.br/cp118670.pdf.

BAGOZZI, D. New WHO guidelines to promote proper use of alternative medicines: Adverse drug reactions to alternative medicines have more than doubled in three years. Disponível em: http://www.who.int/mediacentre/news/releases/2004/pr44/en/index.html.

BALLOTIN V.R; BIGARELLA, L.G; BRANDÃO, A.B.M; BALBINOT, R.A; BALBINOT, S.S; SOLDERA, J. Lesão hepática induzida por ervas: revisão sistemática e metaanálise. Casos da World J Clin: 9 (20): 5490-5513, 2021. doi: 10.12998 / wjcc.v9.i20.5490. 
BARACHO, N. C. D. V. et al. O uso de plantas medicinais como tratamento alternativo no bairro Jardim das Colinas, Itajubá, MG, Brasil. Rev Méd Minas Gerais. 2016; v. 16, n. 2, p. 88-91. Disponível em: http://www.rmmg.org/artigo/detalhes/260.

BARBOSA, D. R; LENARDON, L; PARTATA, A. K. Kava-Kava (Piper methysticum): Uma Revisão Geral. Revista Científica do ITPAC. Araguaína, v. 6, n. 3, jun./2013. Disponível em: https://assets.unitpac.com.br/arquivos/Revista/63/3.pdf.

BASU, A; LUCAS, E. A. Mechanisms and Effects of Green Tea on Cardiovascular Health. Nutrition Reviews. Oklahoma, USA, v. 65, n. 8, p. 361-375, ago./2007. Disponível em: https://academic.oup.com/nutritionreviews/article/65/8/361/1831811.

BATISTUZZO, J. A. O.; ITAYA, M.; ETO, Y. Formulário Médico-Farmacêutico. 3. ed. São Paulo: Pharmabooks, 2006. 670p.

BIERNATH, André. VEJA SAÚDE. 28 plantas medicinais: dos poderes às contraindicações. Disponível em: https://saude.abril.com.br/medicina/plantas-medicinaspoderes-as-contraindicacoes/

BRASIL. Ministério da Saúde. Secretaria de Ciência, Tecnologia e Insumos Estratégicos. Política Nacional de Plantas Medicinais e Fitoterápicos. Brasília, DF, 2006. BRUNTON, L. L. Goodman \& Gilman: As Bases Farmacológicas da Terapêutica. $12^{\mathrm{a}}$ ed. Rio de Janeiro: McGraw-Hill, 2012.

BOHAN A., BOYER, J. L. Mechanisms of hepatotoxicity transport of drugs: implications for cholestatic drug reaction. Semin Liver Dis. v. 22, p. 123-136, 2002. Disponível em: https://www.thieme-connect.com/products/ejournals/abstract/10.1055/s-2002-30099.

CAPARROZ-ASSEF, M.S; DAVIS, S.M; BATISTA, R.C.F; BERSANI-AMADO, F.A; BARONI, S; DANTAS, J.A; CUMAN, R.K.N; BERSANI-AMADO, C.A. Toxicity studies of Cordia salicifolia extract. Acta Sci Health 27: 41-44, 2005.

CHAUDHARY, K. R; BATCHU S. N; SEUBERT, J. M. Cytochrome P450 Enzymes and the Heart. Life, v. 61, n. 10, p. 954-960. 2009

COLET, C. F. et al. Análises das embalagens de plantas medicinais comercializadas em farmácias e drogarias do município de Ijuí/RS. Revista Brasileira de Plantas Medicinais, Botucatu, v. 17, n. 2, p. 331-339, 2015.

DARROZ, J. V.; FUSO, L. C.; BORGES, N. M.; GOMES, A. J. P. S. Utilização de fitoterápicos no tratamento de constipação intestinal. Arq. Cienc. Saúde UNIPAR, Umuarama, v. 18, n. 2, p, 113-119, maio/ago. 2014.

FERREIRA, J.V. Extratos secos do rizoma de kava-kava (Piper methysticum g. forst) avaliação da qualidade, toxicidade aguda, atividades biológicas e biodisponibilidade de kavaína. Tese (Doutorado em Ciências Farmacêuticas) - Universidade Federal de Minas Gerais, 2019. 
GRAIM, J. F. de S. et al . Histologic evaluation of rats' liver after Croton cajucara Benth (sacaca) administration. Acta Cir. Bras., São Paulo, v. 23, n. 2, p. 130134, Apr. 2008. Disponível em:

<http://www.scielo.br/scielo.php?script=sci_arttext\&pid=S0102-

$86502008000200004 \& \operatorname{lng}=$ en\&nrm=iso>. Acessado em 22 Feb. 2021.

HORTO DIDÁTICO DE PLANTAS MEDICINAIS DO HU/CCS. Erva-Cidreira.

Disponível em: https://hortodidatico.ufsc.br/erva-cidreira/.

JUNIOR, V. F. V; PINTO, A. C; MACIEL, M. A. M. Plantas Medicinais: Cura Segura?

Revista Química Nova, São Paulo- SP, v. 28, n. 3, p. 519-528, fev./2005. Disponível em: http://www.scielo.br/pdf/qn/v28n3/24145.pdf.

KIMURA, G. Consumo do chá de hibisco requer moderação: veja os riscos. Exame, 2015. Disponível em: https://exame.com/casual/consumo-do-cha-de-hibisco-requer-moderacaoconheca-os-risco/.

LICHTENSTEIGER, C. A; JOHNSTON, N. A; BEASLEY, V. R. Rhamnus cathartica (Buckthorn) Hepatocellular Toxicity in Mice. Toxicologic Pathology, Washington, United States, v. 25, n. 5, p. 449-452, out./1997. Disponível em: https://journals.sagepub.com/doi/pdf/10.1177/019262339702500503. Acesso em: 26 fev. 2021.

LUNARDELLI, M. J. M; BECKER, M. W; BLATT, C. R. Tradução e validação de algoritmo para identificação de lesão hepática induzida por medicamentos. Revista Contexto \&Amp; Saúde, 20(40), 226-235. 2020. https://doi.org/10.21527/2176-7114.2020.40.226-235

MAZIERO, M., TEIXEIRA, M. P. A expansão da utilização de fitoterápicos no Brasil. In: SALÃO INTERNACIONAL DE ENSINO, PESQUISA E EXTENSÃO, IX, 2017, Santana do Livramento. Material técnico do Fabricante - Quimer Ervas e Especiarias

MORAIS, I. Os benefícios do chá verde. 135. ed. São Paulo: Revista Espaço Aberto. 2012.

OLIVEIRA, H. B. M.; BASTOS, I. Plantas Medicinais e Aromáticas: do Cultivo ao Fitoterápico. Pouso Alegre: IFSULDEMINAS, 2015.

PATEL, S. S. et al. Green tea extract: A potential cause of acute liver failure. World Jornal of Gastroenterology, Houston, United States, v. 19, n. 31, p. 5174-5177, ago./2013. Disponível em: https://www.wjgnet.com/1007-9327/full/v19/i31/5174.htm. Acesso em: 22 fev. 2021.

PEDROSO, R. S; ANDRADE, G; PIRES, R. H. Plantas medicinais: uma abordagem sobre o uso seguro e racional. Physis, v. 31, n. 2, p. 1-19, 2021.

PINN, G. Adverse effects associated with herbal medicine. Australian Family Physician, v. 30, p. 1070-1075. nov./2011. PMID: 11759460. 
RAHMAN. S. Z., SINGHAL K. C. Problems in pharmocovigilance of medicinal products of herbal origin and means to minimize them. Uppsalla Reports 17. 2002.

RODRIGUES, H. G. et al. Efeito embriotóxico, teratogênico e abortivo de plantas medicinais. Revista Brasileira de Plantas Medicinais, Botucatu, v. 13, n. 3, p. 359-366, 2011.

SALGADO, J.M. Benefícios do chá verde vão de emagrecimento a prevenção de doenças. Revista Espaço Aberto. 2021.

SILVA, N. C. S. Tudo que é natural não faz mal? investigação sobre o uso de plantas medicinais e medicamentos fitoterápicos por idosos, na cidade de Iapu- Leste de Minas Gerais." Única Cadernos Acadêmicos 2. 2016.

SILVEIRA, P. F. Perfil de utilização e monitorização de reações adversas a fitoterápicos do programa Farmácia Viva em uma Unidade Básica de Saúde de Fortaleza. Dissertação (Mestrado em Ciências Farmacêuticas) - Universidade Federal do Ceará. Fortaleza, p. 30. 2007.

SINITOX/FIOCRUZ/MS. Estatística Anual dos casos de Intoxicações e Envenenamento no Brasil. Rio de Janeiro. p. 17-87. 2003.

SOCIEDADE BRASILEIRA DE HEPATOLOGIA. Toxicidade hepática de chás, ervas e fitoterápicos. Disponível em: http://www.sbhepatologia.org.br/fasciculos/25.pdf.

SOLDATELLI, M. V., RUSCHEL, K., ISOLAN, T. M. P. Valeriana offi cinalis: uma alternativa para o controle da ansiedade odontológica?. Stomatos, Canoas - RS, v. 16, n. 30, p. 89-95, jun./ 2010. Disponível em: https://docplayer.com.br/16483660-Valeriana-officinalisuma-alternativa-para-o-controle-da-ansiedade-odontologica.html.

VILAR, D. A. et al. Plantas Medicinais: Um Guia Prático. Sergipe: IFS, 2019. Disponível em: www.ifs.edu.br/images/EDIFS/ebooks/2019.2/E-Book_-

_Plantas_mediciais_um_guia_prático_ccompressed.pdf.

YAMAZAKI, Y; HASHIDA, H; ARITA A; HAMAGUCHI K; SHIMURA F; High dose of commercial products of kava (Piper methysticum) markedly enhanced hepatic cytochrome P450 1A1 mRNA expression with liver enlargement in rats, Food and Chemical Toxicology, v. 46, n. 12, p. 3732-3738, 2008, ISSN 0278-6915, https://doi.org/10.1016/j.fct.2008.09.052.

YANG, N; SUN, R; LIAO, X; AA, J; WANG, G. UDP-glucuronosyltransferases (UGTs) and their related metabolic cross-talk with internal homeostasis: A systematic review of UGT isoforms for precision medicine. Pharmacol Res. 121:169-183, 2017. 


\section{Declaração de Interesse}

Os autores declaram não haver nenhum conflito de interesse

\section{Financiamento}

Financiamento próprio

\section{Colaboração entre autores}

L. M. S; W. P; K. G. S. S; M. H. P.C e R.

$S$. $P$. realizaram a revisão de literatura $e$ procederam a escrita do presente estudo, e B.S.S.L delineou o estudo e realizou a revisão da versão final do trabalho. 